\title{
Impression Generation of Indonesian Cultural Paintings for Mobile Application with Culture Dependent Color-Impression Metric Creation Contents
}

\author{
Devira Nanda Kuswhara, Ali Ridho Barakbah, Nur Rosyid Mubtadai, \\ Yuliana Setiowati \\ Electronic Engineering Polytechnic Institute of Surabaya \\ Jalan Raya ITS Surabaya 60111, Indonesia \\ E-mail:devira@student.eepis-its.edu, \{ridho, rosyid, yuliana\}@pens.ac.id
}

\begin{abstract}
Painting is one of complex image reflecting observations and feelings of the artist to the environment. This condition extends the need of painting impression generation system since common people with lack of art experience would have difficulties to interpret the painting. From this point of view we presents a new model to provide representative impressions of paintings by providing a color-impression metric taken from public survey and implement it for mobile application. The new model provides analytical functions to generate the representative impression of the image query. The functions consist of two main section: (1) The cultural-dependent color-impression metric creation which consist of conducting survey, applying normalized 3D color vector quantization to image dataset, generating image-impression metric, and generating colorimpression metric; and (2) Impression generation of image query which consist of applying normalized 3D color vector quantization to image query and measuring the similarity between image query and color-impression metric. To perform our proposed impression generation system, we examine our system with Indonesian cultural image dataset and 5 different mobile devices. Our proposed system performs main color impression precision result with average precision of more than $60 \%$. Brightness intensity and zooming affects the retrieved impressions. Rotating captures of an image generate the same retrieved impressions. The system also performs average response time vary in range 41263 to 117434 milliseconds from all devices.
\end{abstract}

Keywords: impression generation system, color based impression, cultural computing, mobile application. 


\section{INTRODUCTION}

Painting is a living artistic tradition which integrates respected philosophy, aesthetics, and cultural values and beliefs. Appreciating painting means to understand the languages that all people speak that cut across racial, cultural, social, educational, and economic barriers and to enhance cultural appreciation and awareness. Irrespective of the precious values contained on it, painting is one of complex images to human which is often expressed in abstract way. It needs more sensibility and sensitivity of human to interpret since visual impression may differ in each person. Unless having lot of experiences in appreciating art, common people will have difficulties to get the impression of the painting.

\section{RELATED WORKS}

We refer to several works about discovering impression of cultural property using computational method on representative color and color feature as related works. Barakbah et al. [1] have been proposed a method called 3D color vector quantization where the color information of the image is extracted using the histogram from RGB color space and then quantized in $5 \times 5 \times 5$ size of RGB color space to 125 positions in the RGB color spaces. Shiranita et al. [2] presented an impression-word-giving system for images based on colors extracted using Lab Color Space. The main color is determined by $85 \%$ of all pixels in the image. Then they calculated the minimum distance and the average distance to 160 impressions used. Comparisons are determined in accordance with the impression of the source image. Suhardijanto et al. [3] presented a model explaining the relation between culture and emotion-oriented color which is used for image retrieval system with aspects of human emotion. Sasaki et al. [4] presented a dynamic image-query creation and metadata extraction method with semantic correlation computation between color-combinations and impressions of multiple image data. This image-query creation method representing impression of color makes it possible to expand the range of image retrieval for a large number of image data of cultural property in digital archives.

\section{ORIGINALITY}

This paper proposes an impression generation system of Indonesian cultural painting images with a new model for selecting and representing the image impressions by creating culture dependent color-impression metric obtained from public survey and implementing the system to a mobile application. The objective of the proposed system in this paper is to apprehend user intention to get the representative impressions of the paintings related to human emotional sense. We implement 231 Indonesian cultural images consisting five categories of painting stream: abstractionism, naturalism, expressionism, realism, and romance; in our survey to collect impressions. The architecture of our proposed system is shown in Figure 1. 


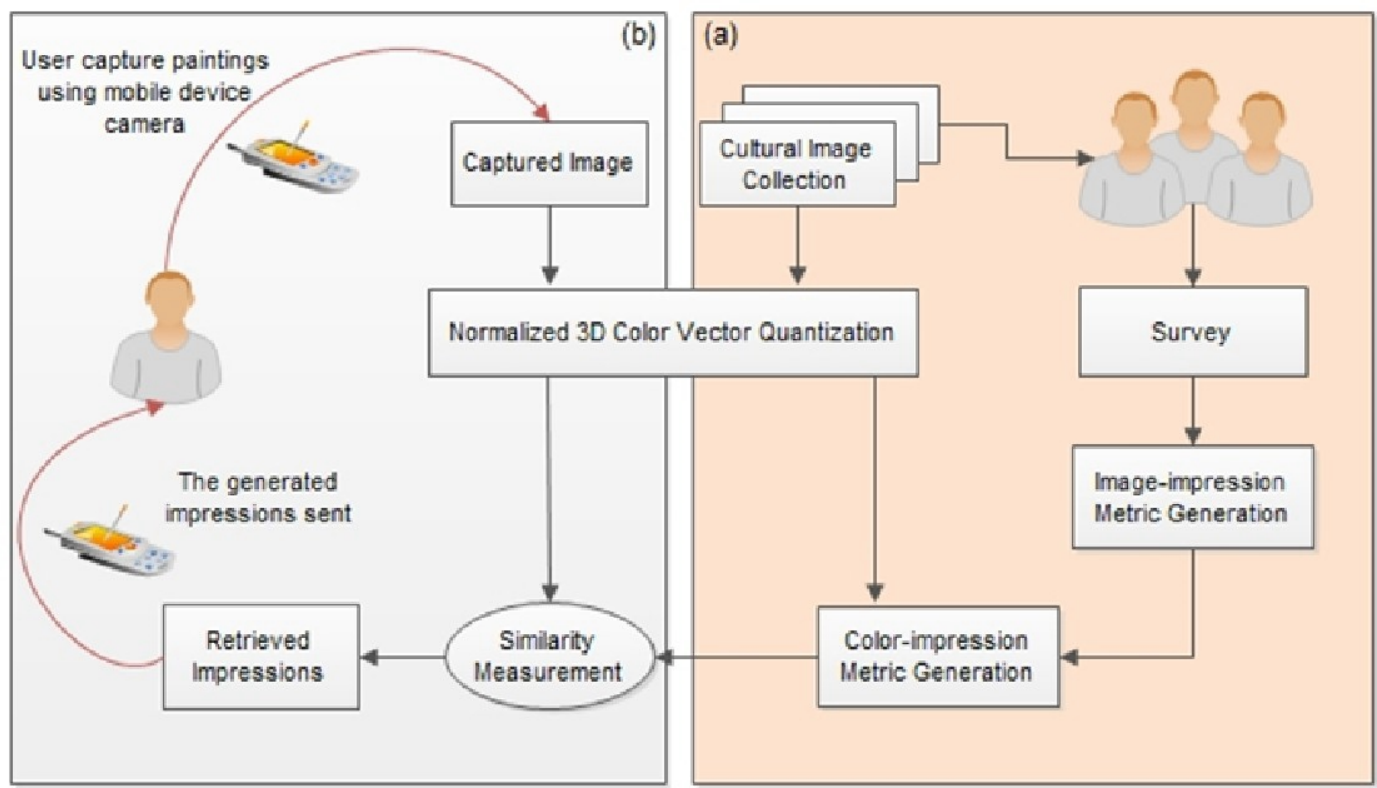

Figure 1. The architecture of the proposed impression generation system: (a) The cultural-dependent color-impression metric creation, and (b) Impression generation of image query

Our proposed system presents a supporting tool to ease user experience in appreciating cultural painting by providing representative impressions of the captured painting. This system will bring a significant contribution especially to help communicating the ideas between the artists and the painting observers. Furthermore, the system will develop human aesthetic experience in order to be able to appreciate art that encompass social and cultural meanings and implications.

\section{IMPRESSION GENERATION ANALYTICAL FUNCTION}

\subsection{The Cultural-dependent Color-Impression Metric Creation}

The function consists of several steps to create culture dependent colorimpression metric creation: (1) Impression Survey, (2) Normalized 3D Color Vector Quantization, (3) Image-impression metric generation, and the last (4) Color-Impression metric generation.

\section{(1) Impression Survey}

Figure 2 shows the design of a web-based polling system, where users fill the polling by choosing at least one of 30 impressions related to Indonesian culture that have been provided on the list. The result of the survey will be converted to a raw user-impression metric. 


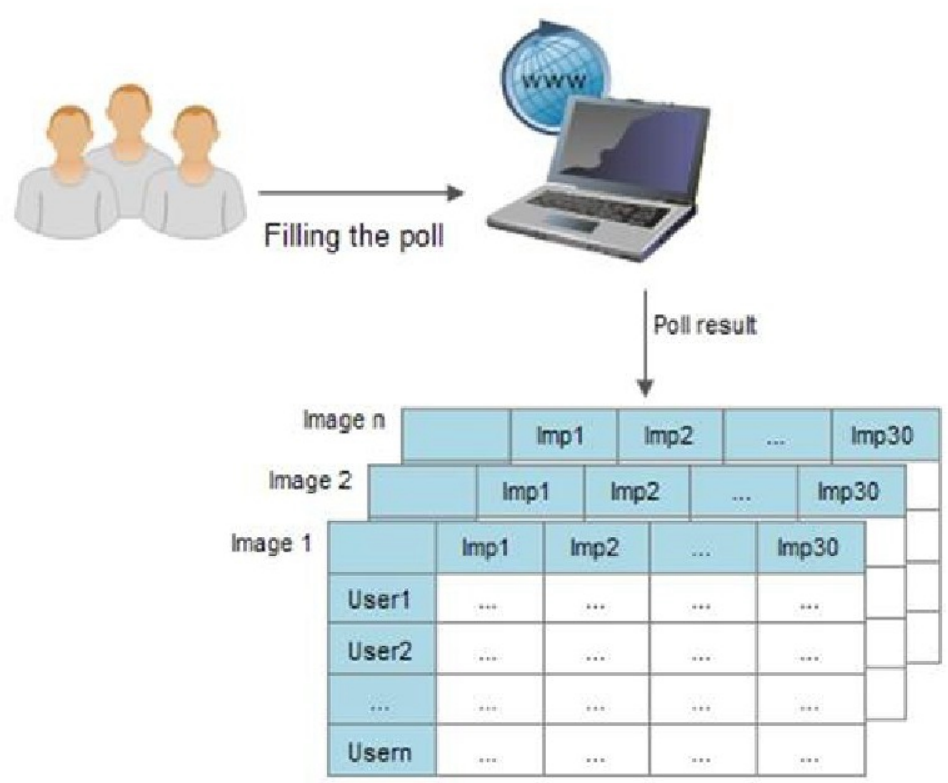

Figure 2. Polling system design

\section{Image Dataset}

In this process, each user will finish the polling of 8 images of Indonesian cultural painting which are randomly generated among the 231 images dataset consist of 5 categories: naturalism, expressionism, abstract, realism and romance. There are 34 paintings of abstract, 28 paintings of naturalism, 57 paintings of expressionism, 20 of paintings romance and 109 paintings of realism. Those are all painted by Indonesian painters.

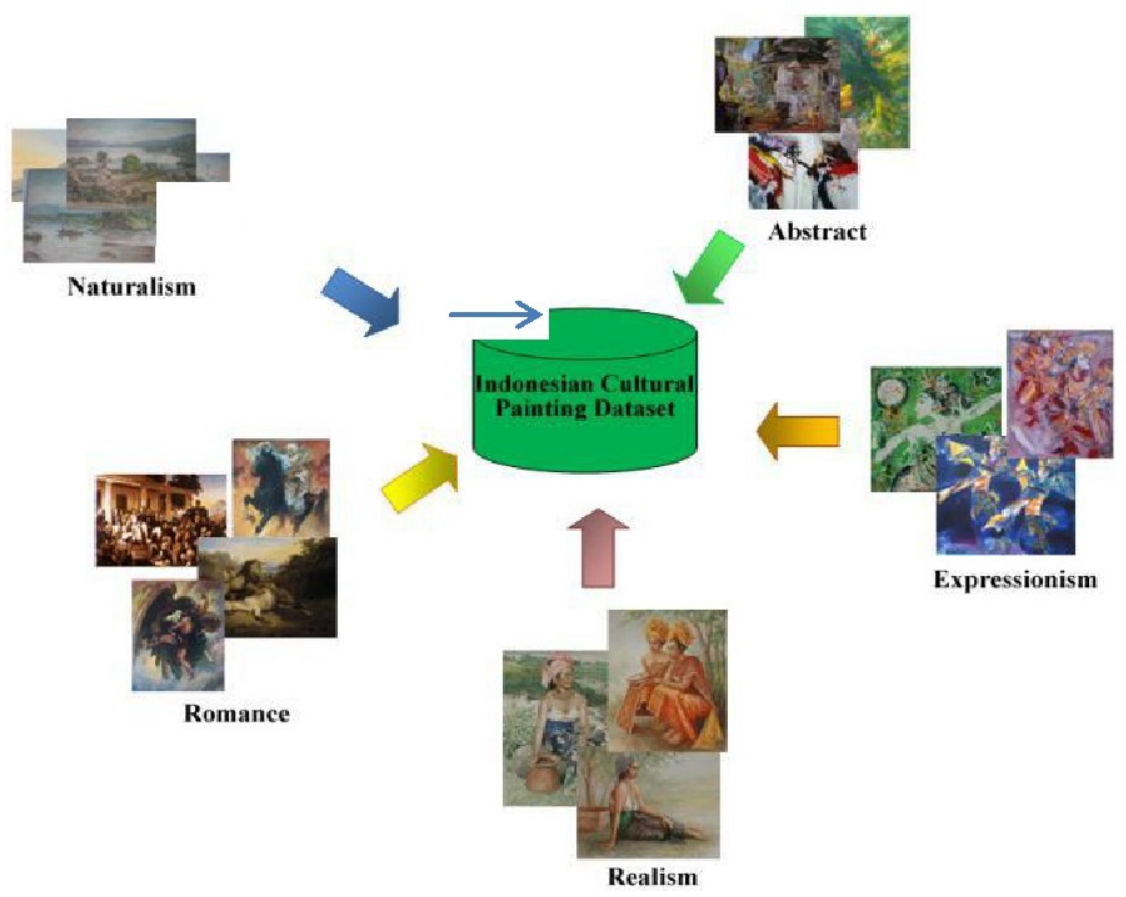

Figure 3. Painting categories 


\section{Impressions List}

The Japanese impression set which is known as Kansei have 180 impressions related to colors. A recent study [5] presented research about method to classify those color-impressions based on cultural perception. The research worked using 17 impressions out of 180. In our proposed system, we implement 30 impressions out of 50 from recent work [6] which is inspired from the Kansei list. The selected impressions are considered suitable with Indonesian culture. The Impression list is shown at Table 1.

Table 1. Impressions list

\begin{tabular}{|l|l|l|}
\hline \multicolumn{3}{|c|}{ Impressions List } \\
\hline Aman & Curiga & Letih \\
\hline Bersemangat & Sopan & Ragu \\
\hline Bingung & Khawatir & Sepi, sunyi \\
\hline Khilaf & Cinta & Menarik \\
\hline Malu, segan & Sombong, angkuh & Damai, tenteram, tenang \\
\hline Kejam, marah & Cantik, indah & Putus asa \\
\hline Suci, mulia & Romantis & Kacau \\
\hline Dengki, cemburu & Nekad & Mengagumkan, mempesona \\
\hline Sedih, perih & Sabar & Resah, risau \\
\hline Ikhlas & Sensual & Gembira, senang \\
\hline
\end{tabular}

The impression polling had been started since $15^{\text {th }}$ October to December $10^{\text {th }} 2013$ with 120 voters filling the poll. The polling process is described by following points.

1. The voters access the web address of polling system and click the start button.

2. The system automatically generates 8 random images out of 231 image collections in sliding template.

3. Each image is displayed with a set of check boxes containing the impression word.

4. The voters must choose at least one impression for each image.

5. The polling process is ended by clicking the finish button.

\section{(2) Normalized 3D Color Vector Quantization}

This step is used for extract the color features of image dataset and image query given by users. The In this step, the color information of the image dataset and the image query is extracted using the histogram from 3D-Color Vector Quantization of RGB color space. According to the recent study [1], 3D color vector quantization is $64 \times 64 \times 64$ quantization size of the RGB color space so that it can be represented with 125 positions in the RGB color space.

Considering that the sizes of image dataset could be various, calculation of the local average is needed to normalize the features. In case of two images 
below that have different size of pixels, the colors histogram shows that the second image produces a bigger value than the first one. This can cause an error while generating representative colors because a large number of nondominant colors are generated from second image. Figure 4 shows the process of the normalized 3D vector quantization.

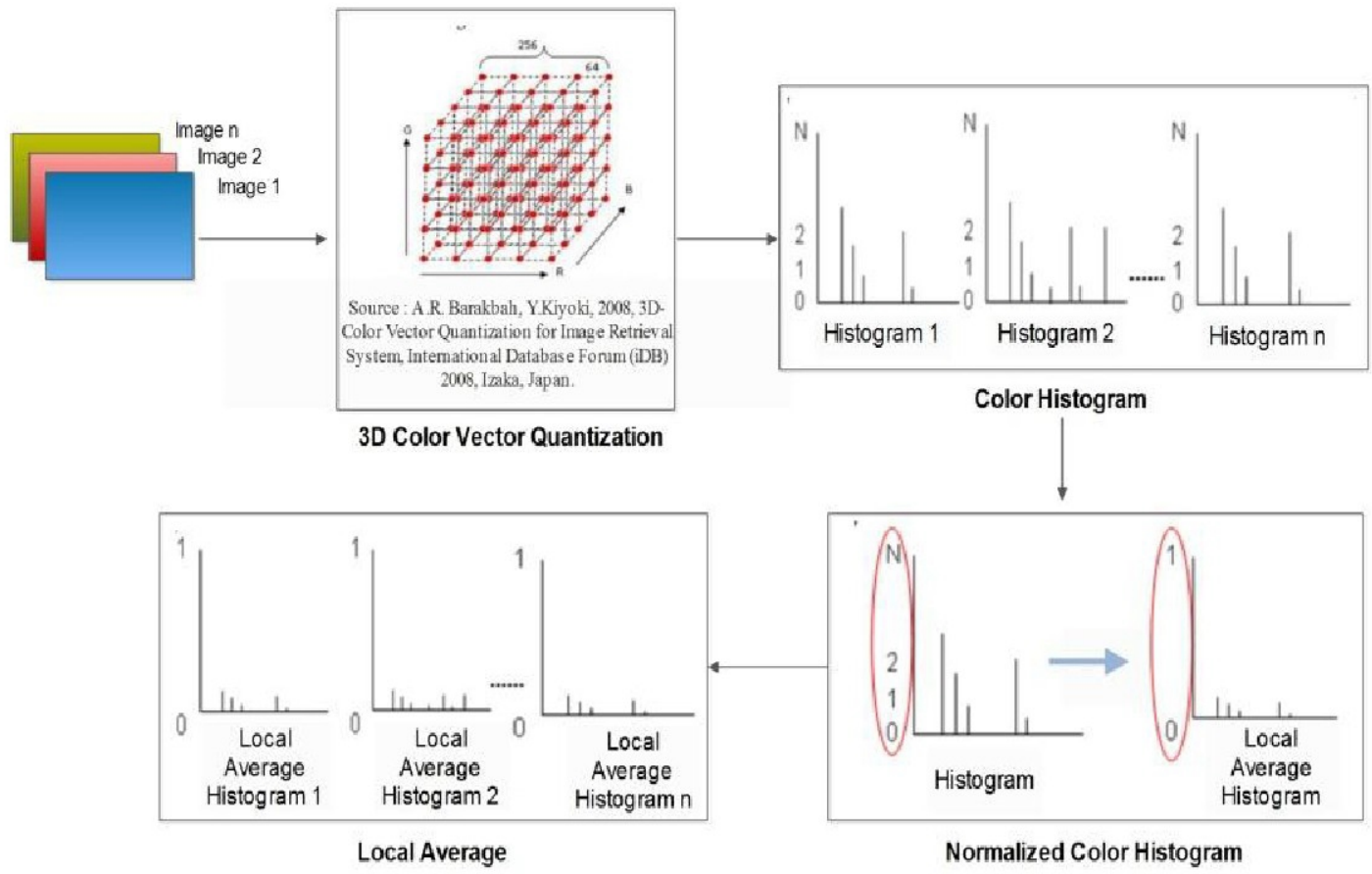

Figure 4. Normalized 3D color vector quantization of image dataset process: process of generating image histogram, histogram output, process of normalized image histogram, histogram final output.

The outcome of normalized 3D color vector quantization of all image dataset processes is a set of local average histograms. The local average of each image dataset will be indexed into an image color feature metric. The metric contains information of color features of multiple images. The table of image color feature metric is shown in Table 2.

Table 2. Image color feature metric

\begin{tabular}{|c|c|c|c|c|c|c|c|c|c|c|c|}
\hline Image & $\boldsymbol{f}_{\boldsymbol{1}}$ & $\ldots$ & $\boldsymbol{f}_{\mathbf{2 5}}$ & $\ldots$ & $\boldsymbol{f}_{\boldsymbol{5 0}}$ & $\ldots$ & $\boldsymbol{f}_{\mathbf{7 5}}$ & $\ldots$ & $\boldsymbol{f}_{\mathbf{1 0 0}}$ & $\ldots$ & $\boldsymbol{f}_{\boldsymbol{1 2 5}}$ \\
\hline $\operatorname{Img}_{1}$ & $\mathrm{n}_{1,1}$ & $\ldots$ & $\mathrm{n}_{1,25}$ & $\ldots$ & $\mathrm{n}_{1,50}$ & $\ldots$ & $\mathrm{n}_{1,75}$ & $\ldots$ & $\mathrm{n}_{1,100}$ & $\ldots$ & $\mathrm{n}_{1,125}$ \\
\hline$\ldots$ & $\mathrm{n}_{., 1}$ & $\ldots$ & $\mathrm{n}_{\ldots, 25}$ & $\ldots$ & $\mathrm{n}_{. .50}$ & $\ldots$ & $\mathrm{n}_{., 75}$ & $\ldots$ & $\mathrm{n}_{\ldots, 100}$ & $\ldots$ & $\mathrm{n}_{., 125}$ \\
\hline $\operatorname{Img}_{n}$ & $\mathrm{n}_{\mathrm{n}, 1}$ & $\ldots$ & $\mathrm{n}_{\mathrm{n}, 25}$ & $\ldots$ & $\mathrm{n}_{\mathrm{n}, 50}$ & $\ldots$ & $\mathrm{n}_{\mathrm{n}, 75}$ & $\ldots$ & $\mathrm{n}_{\mathrm{n}, 100}$ & $\ldots$ & $\mathrm{n}_{\mathrm{n}, 125}$ \\
\hline
\end{tabular}

Where $f_{i}$ is color feature, $i$ is color feature cluster index of 125 positions in the RGB color space, and $n$ is total number of image pixels grouped by color feature cluster, and Img is image query of image dataset. 


\section{(3) Image-Impression Metric Generation}

In the web-based polling system, users are asked to fill the polling by choosing at least one of 30 impressions related to Indonesian culture that have been provided on the list. The result of the survey will be converted to a raw user-impression metric. The next step is classifying similar objects in the same groups with optimal centroid. The automatic clustering is used to determine optimum cluster number. Then we use approach of combining the $\mathrm{k}$-means and hierarchical algorithm which is described in [7] as the centroid $\mathrm{k}$-means model is good to optimize the initial centroids. The raw user image impression metric would be dataset for the clustering. All of the processes needed to generate cultural-dependent image-impression metric of image are shown in Figure 5.

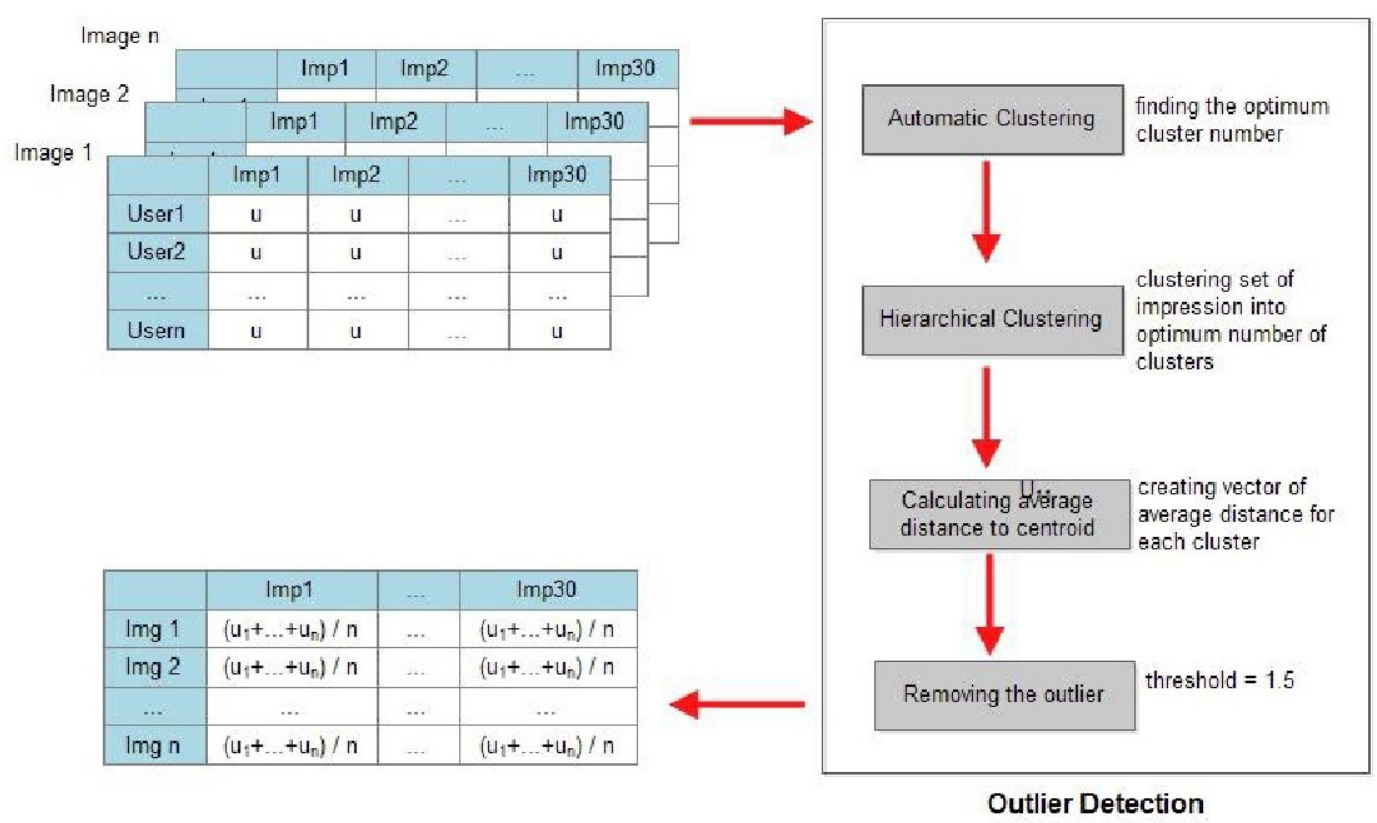

Figure 5. The Image-impression metric generation process

The attribute we need to obtain next is the average distance of cluster member to the centroid. The average can be obtained by calculating mean of dataset distance to centroid within the same cluster. We define a threshold $t$ $=1.5$ to take the value of a specified outlier detection function.

We examine each data using the specified outlier detection function. The function compares the data distance to its centroid to the multiplication of threshold $t$ and average distance $a$. The outlier detection function takes values 1 if value of $\mathrm{d}$ exceeds given threshold multiplication function and takes the value 0 otherwise. The value of outlier detection function is taken to decide whether the data is an outlier or not, where value 1 means outlier and otherwise.

After removing the outlier, the normalization is applied by calculating sum of the total number of impressions for each image. The final value is taken from total number divided by the total user who gives the impression. 
The normalized user image impression vector would be taken to develop image impression metric. The all 231 normalized user image impression vectors of image dataset would be indexed into an image-impression metric.

\section{(4) Color-Impression Metric Generation}

In this subsection, we already have image color feature metric and image impression metric of 231 images dataset. Both metric have important role in creating color-impression metric. We work with both metric to obtain metadata association by using inner product multiplication. The process of color-impression metric generation is shown at Figure 6.

The image impression metric needs to be transposed first due to inner product condition. The inner product multiplication could be implemented only if the number of first metric total column equals with the number of second metric total row. It results a matrix of size $n \times p$, where $n$ is the number of rows in the first matrix (left) and $p$ is the number of columns in the second matrix (right). The equation for implementing inner product function is shown at Equation 1.

$$
M_{1} \times M_{2}=\sum_{i=1}^{n} M_{1_{i}} \times M_{2_{i}}
$$

where $M_{1}$ is the first metric and $M_{2}$ is the second metric and the size or the result metric depends on number of column of $\mathrm{M}_{1}$ and number of row of $\mathrm{M}_{2}$.

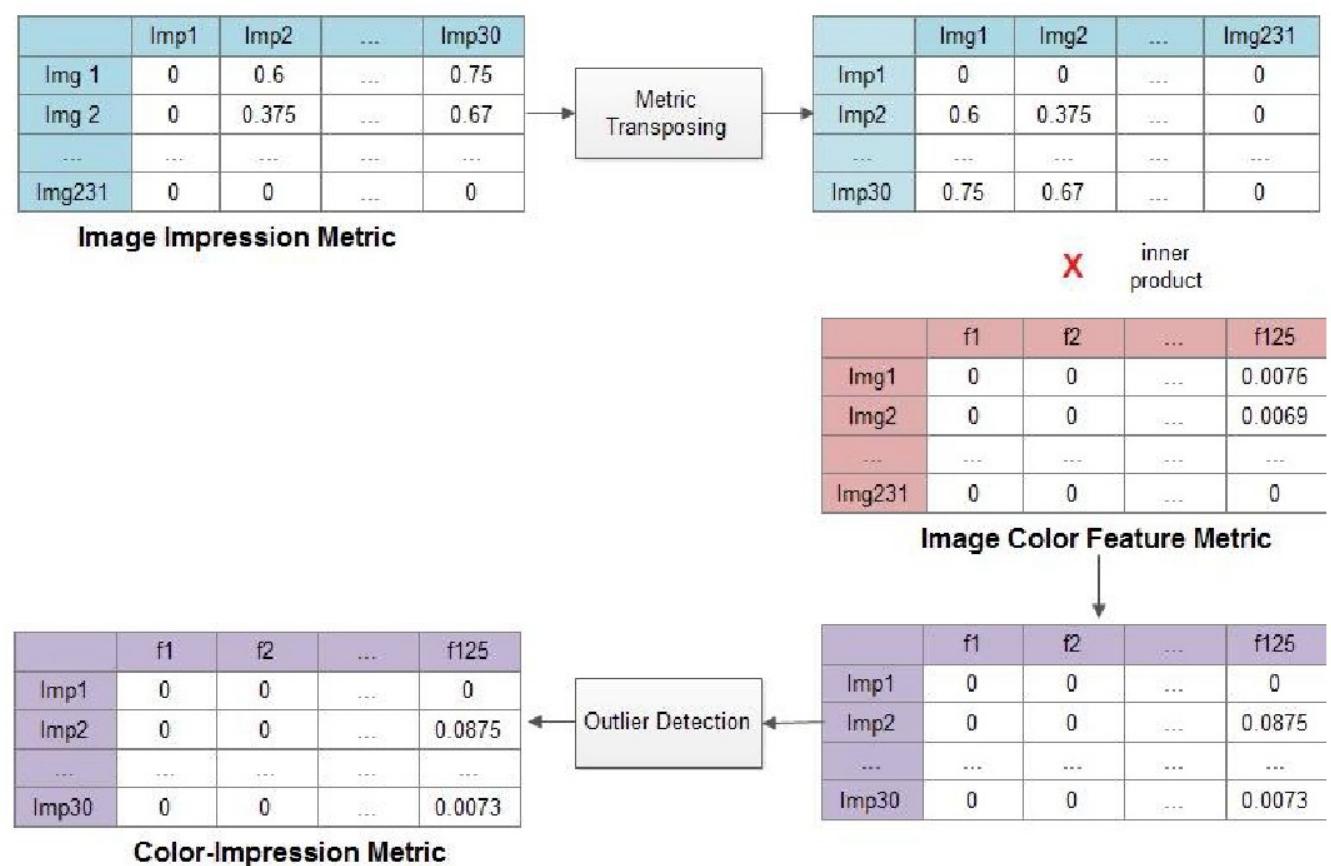

Figure 6. Process of color-impression metric generation

The inner product of both metric results a new metric which classifies the representative color feature related to impression based on impression 
polling on Indonesian cultural painting. Thus we call the metric as culturaldependent.

Like the previous step, after multiplying both metric, we examine each data using the specified outlier detection function. The function compares the data distance to centroid $d$ to the multiplication function of threshold $t$ and average distance $a$. The outlier detection function takes values 1 if value of $d$ exceeds given threshold multiplication function and takes the value 0 otherwise. The value of outlier detection function is taken to decide whether the data is an outlier or not in which value 1 means outlier and otherwise.

The generated color-impression metric needs to be normalized to prevent the impression dominating the computed dissimilarity and variables that are measured in small valued units with very little contribution. The normalization is applied by calculating sum of the total number of impressions for each impression (each row). The determinant $d t$ value is taken from total number of each row like shown in Equation 2.

$$
d t=\sum_{i=1}^{k} n_{i}
$$

where $n$ refers to value specified on the color feature cluster and $i$ refers to index of the cluster. If the determinant values 0 , it means the specified impressions contribute very little in the computing. Therefore, the specified impression should be removed.

\subsection{Impression Generation of Image Query}

In this section, we build the main function which specified our system objective. The cultural-dependent color-impression metric would be implemented to the mobile application to measure the similarity between each impression metadata and image query captured by user. We implement the function to device with Android operating system.

\section{(1) Normalized 3D Color Vector Quantization}

Since the size of image pixels captured by mobile device is large in number, we resize the image to $150 \times 200$ pixels to optimize the mobile computing and response time. Larger size of pixels may cause long time in computing especially in clustering color features. The illustration of the resizing process is shown at Figure 7.

The resized picture is taken to implement the color feature extraction. The conversion from user's image query to color feature metadata equals with the same previous color vector quantization process on image dataset. The resized image query is extracted using the histogram from 3D-Color Vector Quantization of RGB color space. According to the recent study [1], 3D color vector quantization is $64 \times 64 \times 64$ quantization size of the RGB color space so that it can be represented with 125 positions in the RGB color space. 

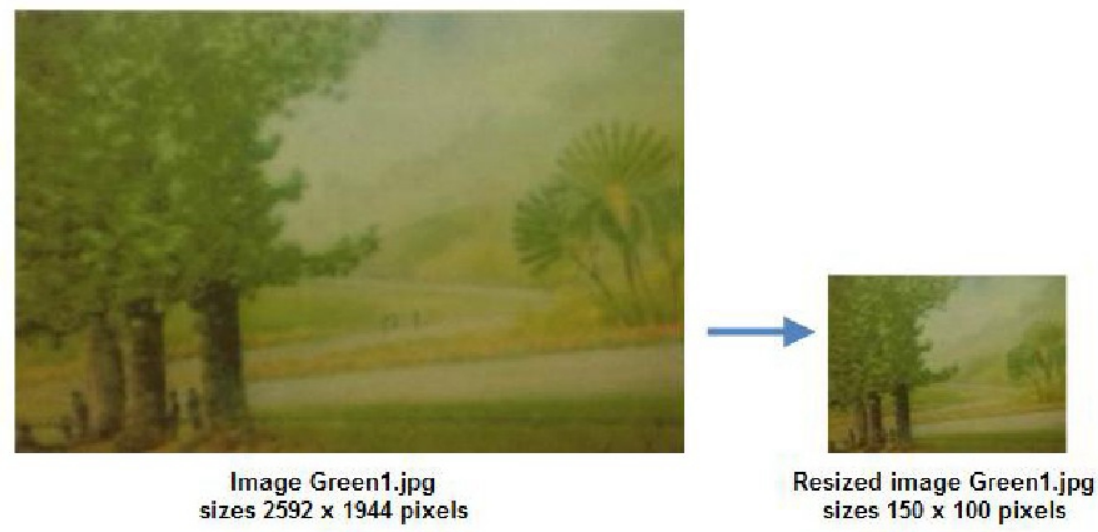

Figure 7. The illustration of resizing image

\section{(2) Similarity Measurment}

The distinct function on this section is measuring similarity between image query and impression metadata on cultural-dependent colorimpression metric. In recent work [8], Qian et. al. analyzed those two distance measures based on feature vectors normalized by image size and experiment with them in the context of color image database. The research concluded that the cosine angle distance, in general, works equally well for image databases. We can use the cosine similarity between the image query vector and color-impression vector as a measure of the score of the representative impression for that image query. The resulting scores can then be used to select the top-scoring impressions for a query. The implementation is shown at Equation 3.

$$
\text { Similarity }=\cos \theta \frac{A . B}{\|A\||| B \|}==\frac{\sum_{i=1}^{n} A_{i} x B_{i}}{\sqrt{\sum_{i=1}^{n}\left(A_{i}\right)^{2}} \sqrt{\sum_{i=1}^{n}\left(B_{i}\right)^{2}}}
$$

Where $n$ is the number of color metadata clusters, $A$ is representative color of image query, and $B$ is representative color of impression. The result will be ranked in descend to find the most similar impression for the image query.

\section{EXPERIMENTAL STUDY}

To perform our proposed impression generation of cultural painting system, we examine our system with Indonesian cultural painting dataset consisting of 2 multicolor red dominant paintings, 2 multicolor blue dominant paintings, and 2 multicolor blue dominant paintings. Several experiments are applied for each category of dominant color. To analyze the precision, we compare the similarity of impressions retrieved from application testing and impressions retrieved from the highest color feature of the image. To analyze the performance, we compare the application performance running in several devices. We examine our system with several collections of Indonesian cultural painting. Example of paintings are shown at Figure 8. 


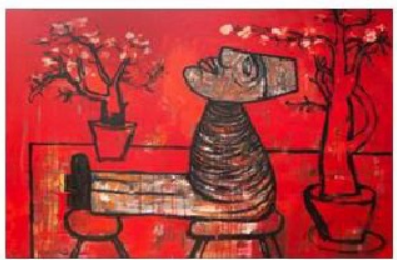

(1)

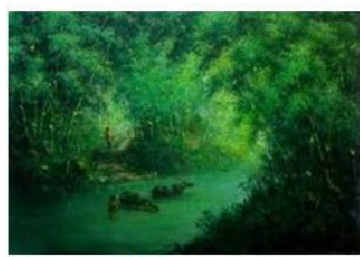

(4)

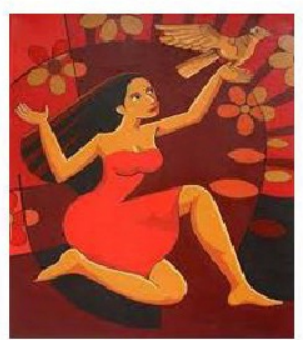

(2)

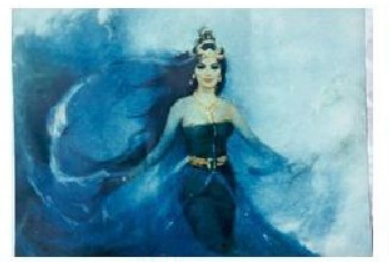

(6)

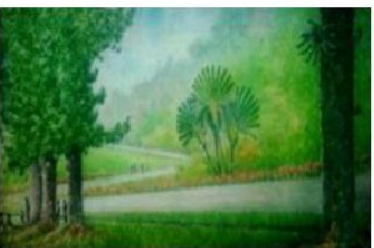

(3)

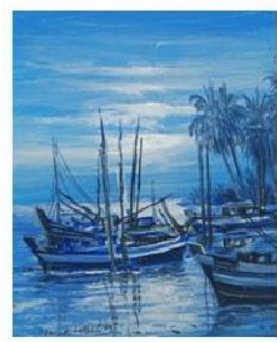

(7)

Figure 8. Example of paintings for experiment

\subsection{Experiment in Measuring Impression Precision}

Here we conduct an experimental study to analyze the precision of the generated impression. Performance comparison is obtained from comparing image retrieved impressions to its main color-impression. Ground-truthing of a large image dataset is a resource and cost intensive work. The only way to present performance objectively is through precision, which is defined in Equation 4.

$$
\begin{array}{r}
\text { Precision }=\text { Number of relevant main color impressions } \\
\text { Total number of retrieved main color impressions }
\end{array}
$$

The words inside Table 3 show a set of impressions generated by application from Painting 1.

Table 3. Experiment result of painting 1

\begin{tabular}{|c|l|}
\hline Rank & \multicolumn{1}{|c|}{ Retrieved Impressions } \\
\hline 1 & Cantik, indah \\
\hline 2 & Ikhlas \\
\hline 3 & Suci, mulia \\
\hline 4 & Cinta \\
\hline 5 & Sabar \\
\hline 6 & Merangsang \\
\hline 7 & Bersemangat \\
\hline 8 & Damai, tenteram, tenang \\
\hline 9 & Sopan \\
\hline 10 & Gembira, senang \\
\hline
\end{tabular}


We investigated the main colors of the images by looking at the clustering result of color feature extraction on step color vector quantization. The rank of main colors was determined by the sum of pixels of the main colors in order. The main color feature is shown at Table 4. We compare the impressions of 3 main colors of image and the retrieved impressions from Table 3. All main color impressions matched the retrieved impressions list.

Table 4. Main color feature of painting 1

\begin{tabular}{|c|c|c|c|l|}
\hline \multirow{2}{*}{ Rank } & \multicolumn{3}{|c|}{ Main Color } & \multirow{2}{*}{ Main color impression } \\
\cline { 2 - 4 } & $\mathrm{R}$ & $\mathrm{G}$ & $\mathrm{B}$ & \\
\hline 1 & 127 & 127 & 127 & Bersemangat \\
\hline 2 & 191 & 191 & 127 & Cinta \\
\hline 3 & 191 & 127 & 127 & Cantik-indah \\
\hline
\end{tabular}

Table 5. Average impression precision of painting collections

\begin{tabular}{|c|l|l|c|}
\hline Painting & \multicolumn{1}{|c|}{ Retrieved Impressions } & \multicolumn{1}{c|}{$\begin{array}{c}\text { Main } \\
\text { color-impressions }\end{array}$} & Precision \\
\hline 1 & $\begin{array}{l}\text { Cantik-indah, suci-mulia, sabar, } \\
\text { bersemangat, cinta, ikhlas, damai- } \\
\text { tenteram-tenang, khawatir, } \\
\text { mengagumkan-mempesona. } \\
\text { gembira-senang }\end{array}$ & $\begin{array}{l}\text { Bersemangat, cinta, } \\
\text { cantik-indah }\end{array}$ & $100 \%$ \\
\hline 2 & $\begin{array}{l}\text { Cantik-indah, cinta, suci-mulia, } \\
\text { menggoda, mengagumkan- } \\
\text { mempesona, kacau, sabra, ikhlas, } \\
\text { damai-tenteram-tenang, sopan }\end{array}$ & $\begin{array}{l}\text { Cantik-indah, cinta, } \\
\text { cantik-indah }\end{array}$ & $100 \%$ \\
\hline 3 & $\begin{array}{l}\text { Ikhlas, menarik, suci-mulia, } \\
\text { khawatir, damai-tenteram- } \\
\text { tenang, gembira-senang, } \\
\text { bersemangat, putus asa, aman, } \\
\text { sabar }\end{array}$ & $\begin{array}{l}\text { Ikhlas, putus asa, } \\
\text { khawatir }\end{array}$ & $100 \%$ \\
\hline 4 & $\begin{array}{l}\text { Ikhlas, suci-mulia, bersemangat, } \\
\text { gembira-senang, aman, sabar, } \\
\text { damai-tenteram-tenang, } \\
\text { menarik, cantik-indah, khawatir }\end{array}$ & $\begin{array}{l}\text { Sabar, cantik-indah, } \\
\text { mengagumkan- } \\
\text { mepesona }\end{array}$ & $66.67 \%$ \\
\hline 5 & $\begin{array}{l}\text { Gembira-senang, khawatir, } \\
\text { menarik, damai-tenteram-tenang, } \\
\text { suci-mulia, bersemangat, sedih- } \\
\text { perih, aman, putus asa, malu- } \\
\text { segan }\end{array}$ & $\begin{array}{l}\text { Sedih-perih } \\
\text { Gembira-senang, khawatir, } \\
\text { menarik, damai-tenteram-tenang, } \\
\text { suci-mulia, bersemangat, sedih- } \\
\text { perih, aman, putus asa, malu- } \\
\text { segan }\end{array}$ & $33.33 \%$ \\
\hline 6 & & $0 \%$ \\
\hline 6 & & \\
\hline
\end{tabular}


From the experiment results, the impression precision was measured by comparing the top three main color impressions to the retrieved impressions provided by the application. Main color was determined by the highly count of color feature clusters. The centroid cluster represents the main color, and the main color impression is determined by impression which has the highest count of color feature on the certain cluster. The experiments showed that the three main color impressions matched the top ten retrieved impressions averagely for more than $60 \%$.

\subsection{Experiments in Various Captures}

Here we conducted an experimental study to analyze the generated impressions taken from several way of capturing. We select top ten high rank impressions and measure the similarity of each capture mode to the normal mode of the capture category. Our system was examined to brightness based captures, rotating captures, zooming capture. We obtained the similarity value by calculate the relevant retrieved impressions divided by total number of retrieved impressions.

Brightness intensity did affect and bring significant difference in retrieved impressions. The color feature of each captured image is different to each other due to the different intensity of brightness. Thus, the generated impressions of one capture are different to the other. The retrieved impressions of bright mode have similarity to the retrieved impressions normal mode for averagely 50\%. The retrieved impressions of dark mode have similarity to the retrieved impressions normal mode for less than $20 \%$. The experiments results are shown at Table 6.

Table 6. Similarity of impressions generated from brightness based captures

\begin{tabular}{|c|c|c|}
\hline Painting & $\begin{array}{c}\text { Similarity of impressions by } \\
\text { Bright mode }\end{array}$ & $\begin{array}{c}\text { Similarity of } \\
\text { impressions by Dark } \\
\text { mode }\end{array}$ \\
\hline 1 & $50 \%$ & $10 \%$ \\
\hline 2 & $40 \%$ & $10 \%$ \\
\hline 3 & $60 \%$ & $20 \%$ \\
\hline 4 & $50 \%$ & $10 \%$ \\
\hline 5 & $50 \%$ & $10 \%$ \\
\hline 6 & $50 \%$ & $20 \%$ \\
\hline
\end{tabular}

In other experiment, we analyze that rotating capture of painting does not affect and bring no difference in retrieved impressions. This was caused by while captured image is being rotated, the new image had the same color features with previous image. The retrieved impressions of each position have similarity to the retrieved impressions of other positions exactly $100 \%$. The experiments results are shown at Table 7. 
Table 7. Similarity of impressions generated from rotating captures

\begin{tabular}{|c|c|c|c|}
\hline Painting & $\begin{array}{c}\text { Similarity of } \\
\text { impressions by } \\
\mathbf{9 0} \text { capture mode }\end{array}$ & $\begin{array}{c}\text { Similarity of } \\
\text { impressions by } \\
\mathbf{1 8 0} \text { capture } \\
\text { mode }\end{array}$ & $\begin{array}{c}\text { Similarity of } \\
\text { impressions by } \\
\mathbf{2 7 0} \text { capture mode }\end{array}$ \\
\hline 1 & $100 \%$ & $100 \%$ & $100 \%$ \\
\hline 2 & $100 \%$ & $100 \%$ & $100 \%$ \\
\hline 3 & $100 \%$ & $100 \%$ & $100 \%$ \\
\hline 4 & $100 \%$ & $100 \%$ & $100 \%$ \\
\hline 5 & $100 \%$ & $100 \%$ & $100 \%$ \\
\hline 6 & $100 \%$ & $100 \%$ & $100 \%$ \\
\hline
\end{tabular}

We also found that zooming capture bring small difference in retrieved impressions. The difference in retrieved impression caused by the different color feature of each captured image. Though having different color feature, the retrieved impressions were quite similar to each other. From the results, the retrieved impressions of zoom 1 capture have similarity to the retrieved impressions normal mode for averagely above $80 \%$. The retrieved impressions of zoom 2 capture have similarity to the retrieved impressions normal mode for more than $80 \%$. The experiments results are shown at Table 8.

Table 8. Similarity of impressions generated from zooming captures

\begin{tabular}{|c|c|c|}
\hline Painting & $\begin{array}{c}\text { Similarity of impressions by } \\
\text { zoom 1 capture mode }\end{array}$ & $\begin{array}{c}\text { Similarity of } \\
\text { impressions by zoom 2 } \\
\text { capture mode }\end{array}$ \\
\hline 1 & $80 \%$ & $80 \%$ \\
\hline 2 & $80 \%$ & $80 \%$ \\
\hline 3 & $90 \%$ & $70 \%$ \\
\hline 4 & $90 \%$ & $100 \%$ \\
\hline 5 & $80 \%$ & $80 \%$ \\
\hline 6 & $70 \%$ & $80 \%$ \\
\hline
\end{tabular}

\subsection{Experiments in Device Performance}

Here we conducted an experimental study to analyze the response time of the device to generate impression. We examined our system with one collection of Indonesian cultural painting and five devices. The specification of the devices is shown at Table 9.

We examine our system to all devices to three of six paintings used on previous experiments. The result is shown at table 4. In Table 4, we perform device performance on executing 3 main processes: (1) RGB Extraction, (2) Color Vector Quantization, and (3) Similarity Measurement. Where D refers to device we used in experiments. Device 1 refers to Huawei Ascend Y300, 2 refers to Samsung Galaxy Ace 2 I8160, 3 refers to Samsung Galaxy Tab 27.0 P3100, 4 refers Huawei Mediapad 7 Vogue to and 5 refers to Samsung Galaxy Note 8.0 N5100. 
Table 9. Device specifications

\begin{tabular}{|c|c|c|c|c|c|}
\hline Spec & $\begin{array}{l}\text { Device1 } \\
\text { (D1) }\end{array}$ & $\begin{array}{c}\text { Device2 } \\
\text { (D2) }\end{array}$ & $\begin{array}{l}\text { Device3 } \\
\text { (D3) }\end{array}$ & $\begin{array}{l}\text { Device4 } \\
\text { (D4) }\end{array}$ & $\begin{array}{c}\text { Device5 } \\
\text { (D5) }\end{array}$ \\
\hline Type & $\begin{array}{c}\text { Huawei } \\
\text { Ascend } \\
\text { Y300 }\end{array}$ & $\begin{array}{c}\text { Samsung } \\
\text { Galaxy } \\
\text { Ace } 2 \\
\text { I8160 }\end{array}$ & $\begin{array}{c}\text { Samsung } \\
\text { Galaxy Tab } \\
27.0 \\
\text { P3100 }\end{array}$ & $\begin{array}{c}\text { Huawei } \\
\text { Mediapad } 7 \\
\text { Vogue }\end{array}$ & $\begin{array}{c}\text { Samsung } \\
\text { Galaxy Note } \\
8.0 \text { N5100 }\end{array}$ \\
\hline OS & $\begin{array}{c}\text { Android } \\
4.1\end{array}$ & $\begin{array}{c}\text { Android } \\
2.3\end{array}$ & $\begin{array}{c}\text { Android } \\
4.0 .3\end{array}$ & $\begin{array}{c}\text { Android } \\
4.1\end{array}$ & $\begin{array}{c}\text { Android } \\
4.1 .2\end{array}$ \\
\hline CPU & $\begin{array}{c}\text { Dual-core } \\
1 \mathrm{GHz} \\
\text { Cortex-A5 } \\
\end{array}$ & $\begin{array}{c}\text { Dual-core } \\
800 \mathrm{MHz}\end{array}$ & $\begin{array}{c}\text { Dual-core } \\
1 \mathrm{GHz}\end{array}$ & $\begin{array}{c}\text { Quad-core } \\
1.2 \mathrm{GHz}\end{array}$ & $\begin{array}{c}\text { Quad-core } \\
1.6 \mathrm{GHz} \\
\text { Cortex-A99 }\end{array}$ \\
\hline Memory & $\begin{array}{c}512 \mathrm{MB} \\
\text { RAM }\end{array}$ & $\begin{array}{c}768 \mathrm{MB} \\
\text { RAM }\end{array}$ & 1 GB RAM & $\begin{array}{l}1 \mathrm{~GB} \\
\text { RAM }\end{array}$ & 2 GB RAM \\
\hline
\end{tabular}

Table 10. Device response time

\begin{tabular}{|c|c|c|c|c|c|c|}
\hline Process & D1 (ms) & $\begin{array}{c}\text { D2 } \\
(\mathbf{m s})\end{array}$ & $\begin{array}{c}\text { D3 } \\
(\mathbf{m s})\end{array}$ & $\begin{array}{c}\text { D4 } \\
(\mathbf{m s})\end{array}$ & $\begin{array}{c}\text { D5 } \\
(\mathbf{m s})\end{array}$ & $\begin{array}{c}\text { Avg } \\
(\mathbf{m s})\end{array}$ \\
\hline 1 & 96 & 102 & 74 & 40 & 27 & 67.8 \\
\hline 2 & 107172 & 116259 & 65299 & 62086 & 40850 & 78333 \\
\hline 3 & 13 & 12 & 10.5 & 8 & 7 & 10.1 \\
\hline Total & 108255 & 117434 & 65959 & 62714 & 41263 & 79125 \\
\hline
\end{tabular}

The system finished in range of 41263 to 117434 milliseconds. From the comparison, Samsung Galaxy Note which has highest specification in CPU have the fastest average response time among all. The rank of the average time response is similar with the rank of device CPU qualification.

\section{CONCLUSION}

In this paper, we have presented an impression generation system of Indonesian cultural painting with cultural-dependent color metric creation for mobile application. Our proposed system is built to apprehend user intention to get the representative impressions of the paintings related to human emotional sense. From four experimental studies, our proposed system performed main color impression precision result with average effectiveness of more than $60 \%$. Brightness intensity affected the retrieved impressions, but the main color impression precision result was quite stable. The process of public impression polling conducted on this system opens big impression outliers, because the impression of every person is different so it cannot obtain a perfect score in the creation of color-impression metric. From device performance experimental studies, our proposed system performed the average response time vary in range 41263 to 117434 milliseconds. The process of clustering of thousands of image color features in color vector quantization leads the time consuming and core processing. Therefore, the system requires high qualification of $\mathrm{CPU}$ above $1 \mathrm{GHz}$ on mobile device to run efficiently. 


\section{REFERENCES}

[1] Ali Ridho Barakbah, Yasushi Kiyoki, 3D-Color Vector Quantization for Image Retrieval System, International Database Forum (iDB) 2008, Izaka, Japan, 2008.

[2] Kazuhiko Shiranita, Kenichiro Hayashi, Akifumi Otsubo, An Impressionword-giving System for Images Based on Colors, http://www.idemployee.id.tue.nl/g.w.m.rauterberg/conferences/CD_d oNotOpen/ADC/final_paper/056.pdf (The journal was accessed on August 2, 2013).

[3] Totok Suhardijanto, Kiyoki Yasushi, Ali Ridho Barakbah, A CultureDependent Metadata Creation Method for Color-based Impression Extraction with Cultural Color Spaces, International Journal of Information Modelling and Knowledge Bases, Vol. XXII, IOS PRESS, March, 2011.

[4] S.Sasaki, Y.Itabashi, Y. Kiyoki, X. Chen, An Image-Query Creation Method for Representing Impression by Color-based Combination of Multiple Images, Information Modeling and Knowledge Bases, Vol. XX, pp. 105-112, 2009.

[5] K. G. D. Tharangie, K. G. K. Kumara, I. Jayasinghe, C. A. Marasinghe, Koichi Yamada,Kansei Color Associations for an Interactive LearningEnvironmentfor Children, http://kjs.nagaokaut.ac.jp/yamada/papers/TH-B2-4.pdf(The journal was accessed on September 2, 2013)

[6] Syamsiar Ferdiansyah, Ali Ridho Barakbah, Nana Ramadijanti, Impression Based Batik Decoration with Culture-dependent Color Impression, D4 Program, Electronic Engineering Polytechnic Institute of Surabaya, 2012.

[7] Kohei Arai and Ali Ridho Barakbah, Hierarchical K-means: An Algorithm for Centroid Initialization for K-means, Reports of the Faculty of Science and Engineering, Saga University, Vol. 36, No.1, 2007.

[8] Gang Qian, Sural, S., Pramanik, S., A Comparative Analysis of Two Distance Measures in Color Image Databases, Proc. International Conference on Image Processing, Vol.1, pp.I-401 - I-404, 2002. 